occupational factors. Figures of smoking by age from the General Household Survey suggest that as far back as the 1930s manual workers smoked more than non-manual workers, and that this difference, which has been widening, could account for some of the differences in mortality between social classes.

Comparison of rates of specific causes of death among immigrants with those of all people in England and Wales underlines the importance of life style on health. There is a growing interest, both official and public, in the effects on health of environment, occupation, and life style. An important method of investigating these effects is the prospective study, which follows up individuals and finds out what happens. Since it is not feasible to predict the health questions that will need to be answered, we aim to develop systems to facilitate the widest range of investigations based on routinely collected national vital and health statistics.

To complement statistics based on current data the OPCS has introduced continuing systems of record linkage: a $1 \%$ random sample of records from the 1971 census linked to records of births, deaths, registered cases of cancer, and migration; records of births linked to those of infant deaths; and ad hoc samples of records of individuals to be studied in terms of mortality or cancer.

Much of the information in these systems comes from the everyday work of clinicians, as do most of the clues of healthy and hazardous ways of life. To improve the information systems and to exploit them we need the collaboration of all in the medical and related professions. They must build up their trust and reliance on statistics. This is happening, but slowly. Needless to say, we attach the greatest importance to safeguarding confidential information, whether on computer or on hard copy. Linking depends on numbers, and no confidential information that could be associated with an individual would ever be released. Output is only anonymous statistics.

I am greatly indebted to colleagues for their help and the Registrar General for permission to publish.

\section{References}

${ }^{1}$ Adelstein, A M, British fournal of Preventive and Social Medicine, 1976, 30, 1.

2 Case, R A M, British fournal of Preventive and Social Medicine, 1956, $10,159$.

${ }^{3}$ Adelstein, A M, in Population Trends 8. London, HMSO, 1977.

${ }^{4}$ Read, D M, and Stanley, F J (editors), Epidemiology of Prematurity. Baltimore, Urban and Schwarzenberg, 1977.

5 Office of Population Censuses and Surveys, Occupational Mortality: Decennial Supplement 1970-72. London, HMSO, 1978.

6 Todd, G F, Occasional Paper No 2. London, Tobacco Research Council, 1976.

? Office of Population Censuses and Surveys, General Household Survey for 1975 and for 1976. London, HMSO, 1978.

${ }^{8}$ Office of Population Censuses and Surveys, Smoking and Professional People. London, HMSO, 1977.

9 Office of Population Censuses and Surveys, Cohort Studies: New Developments. London, HMSO, 1973.

(Accepted 31 fuly 1978)

\title{
Neonatal death in Northern Ireland
}

\author{
MAUREEN J SCOTT, GARTH MCCLURE, MARK MCC REID， J W KNOX RITCHIE, \\ SAMUEL R KEILTY
}

ing and treating severely ill infants needing intensive care.

\section{Summary and conclusions}

A survey of neonatal deaths occurring over two years in Northern Ireland disclosed that many hospitals where babies could be born probably could not be staffed and equipped to deal effectively with major perinatal problems. The incidence of congenital malformations, especially neural tube defects, was high. A reduction in neonatal deaths from this cause might be expected if facilities for antenatal diagnosis and termination of pregnancy were made available, although this raises grave ethical problems. Many infants died of prematurity and the idiopathic respiratory distress syndrome. A considerable reduction in neonatal deaths might be expected with improved care at the place of delivery backed by a regional centre with facilities for transport-

Queen's University of Belfast, Belfast BT12 6BJ

MAUREEN J SCOTT, MD, lecturer, department of community medicine GARTH MCCLURE, MRCP, DCH, senior lecturer in child health

J W KNOX RITCHIE, MD, MRCOG, senior tutor, department of obstetrics and gynaecology

Royal Maternity Hospital and Belfast City Hospital, Belfast

MARK MCC REID, FRCP, DCH, consultant neonatologist

Royal Maternity Hospital and Royal Belfast Hospital for Sick Children, Belfast

SAMUEL R KEILTY, MB, FFARCs, consultant anaesthetist

\section{Introduction}

Yearly neonatal mortality rates in Northern Ireland are higher than in many other developed countries. In a comparison of deaths in the first year of life in 1973 in 17 developed countries the neonatal figure for Northern Ireland was exceeded only by that for Yugoslavia. ${ }^{1}$ During $1965-73$ the neonatal mortality in these countries fell by an average of 3.7 per 1000 live births but that in Northern Ireland fell by only 3.2. Examination of neonatal mortality rates in the United Kingdom ${ }^{1}$ indicates that the figure for Northern Ireland exceeds that in other areas, the 1973 rate of 14.6 per 1000 live births contrasting with 11.1 in England, 12.7 in Scotland, and 10.5 in the Welsh region. Only in the Birmingham, Manchester, Liverpool, and Leeds regions did the neonatal mortality rate exceed 12 , the highest rate being 12.9 in Leeds; in four areas the rate was below 10, that for the East Anglian region being only $9 \cdot 1$.

Recent experience in many centres has shown that providing special or intensive care for high-risk fetuses and neonates may substantially reduce perinatal and neonatal death rates. Furthermore, the fears expressed by many clinicians that the handicap rate among survivors of intensive care would create an increasing problem have proved to be unjustified. ${ }^{2}$ A British working party ${ }^{3}$ convened to report on the prevention of early neonatal mortality and morbidity recommended that "Health authorities should review as a matter of urgency, the arrangements for special care including intensive care of the newborn."

Workers in neonatology in Northern Ireland have for some 
time been concerned about the quantity and quality of care that they can offer. Both equipment and staffing fall far short of government recommendations. ${ }^{4}$ The yearly number of births in Northern Ireland is around 27000 , and there are at present in Belfast 11 consultant paediatricians, including the four academic staff who hold joint appointments with the Queen's University of Belfast. Two paediatricians in Belfast have a special interest in neonatology and have at their disposal one intensive-care cot and 76 special-care cots. A further five intensive-care beds are sited in the Royal Belfast Hospital for Sick Children. These are not specially designated for neonates but neonates are often treated there. Four paediatricians in Northern Ireland have a full-time commitment outside Belfast and have 51 special-care cots available to them. These four paediatricians serve a population of half a million with about 10000 births a year.

There is no full-time consultant paediatrician in the northern area of the province, which has a population of 350000 and 6500 births a year. Two designated posts in this area have proved impossible to fill despite repeated advertisement, though the most recent advertisement may have attracted a suitable person. Paediatric care is provided by visiting consultants and by three part-time general practitioners. Three of the present paediatricians in Northern Ireland are in posts created within the past four years, none of which requires a special interest or training in neonatology. It was thought that if the neonatal mortality rate was to be reduced then services for the sick neonate must be improved and expanded. To assess demands to be made on such facilities detailed information about infants dying in the neonatal period was needed. This study presents some observations based on neonatal deaths that occurred in an "at-risk" population of 53290 live-born infants in Northern Ireland during 1974-5.

\section{Patients and methods}

All infants born alive in Northern Ireland during 1 January 1974 to 31 December 1975 who died before the age of 28 days were included in the study. The Registrar General's Office furnished death certificate numbers and each certificate was inspected. A register was prepared recording the name, date and place of birth, date and place of death, and certified causes of death in each case. Permission was then sought from obstetricians and paediatricians throughout the province to inspect the hospital notes of each infant and its mother, and information relating to the antenatal, perinatal, and postnatal periods was recorded on a prepared questionnaire. This was transferred to punch cards and a counter-sorter used to prepare tables of distributions of the infants by selected factors. Necropsy was performed in only a small proportion of cases, so it was impossible to adopt pathological or clinicopathological classification systems. Deaths were tabulated according to the eighth revision of the International Classification of Diseases ${ }^{5}$ based on information from death certificates and hospital notes. The ICD rules stating that if death is attributed to more than one condition the death shall be classified under the firstmentioned disease were observed.

\section{Results}

During the two-year period 53290 live births occurred in Northern Ireland. Under $1 \%$ took place at home, and the remaining $99 \%$ at one of $\mathbf{5 2}$ hospitals or maternity homes in the province. Forty-four of these were authorised obstetric units, and eight were general hospitals or special units where delivery would not normally take place. These special units included a fever hospital and neurological, alcoholic, convalescent, and gynaecology units. Altogether 708 infants (367 boys, 337 girls, 3 of indeterminate sex, 1 of unknown sex) died before the age of 28 days, a neonatal death rate of 13.3 per 1000 live births. The charts of 648 infants or their mothers or both were traced, but for 60 infants the only information available was that recorded on the death certificates.

Table I lists the major causes of death in the neonatal period. The leading cause was congenital malformation, which was recorded in 219 cases $(31 \%)$. Other common causes were prematurity $(22 \%)$, idiopathic respiratory distress syndrome $(20 \%)$, intrauterine hypoxia or birth asphyxia $(13 \%)$, pneumonia $(4 \%)$, and miscellaneous conditions $(10 \%)$. The miscellaneous category included groups of up to 10 infants dying from various conditions such as rhesus haemolytic disease, haemorrhagic diatheses, septicaemia, meningitis, and other infections. Prematurity was recorded as a contributory factor in $22 \%$ of deaths, respiratory distress syndrome in $2.1 \%$, and hypoxia or $\underline{\text { W }}$ asphyxia in $1.7 \%$.

Table II gives the malformations most commonly recorded. The leading type found was that affecting the neural tube, 29 cases of anencephaly, 41 of spina bifida, seven of hydrocephalus, and eight of encephalocele being recorded. Congenital heart disease was recorded $\overline{\bar{S}}$ in 58 neonatal deaths, and 34 infants had multiple malformationsaffecting several systems, five of them having Down's syndrome. Ten infants had tracheo-oesophageal malformations. No other specific $\overline{\bar{\omega}}$ malformation was recorded in more than four infants.

Birth weight was recorded in 567 cases (table III): $115(20.3 \%)$ of $\stackrel{\mathbb{Q}}{\AA}$ the infants weighed less than $1000 \mathrm{~g}, 126(22.2 \%)$ between 1000 and 0 $1499 \mathrm{~g}, 81(14.3 \%)$ between 1500 and $1999 \mathrm{~g}, 71(12.5 \%)$ between 2000 and $2499 \mathrm{~g}$, and $174(30 \cdot 7 \%) 2500 \mathrm{~g}$ or more. Maturity was. known in 645 cases. In $132(20.5 \%)$ the pregnancy did not reach 28 weeks' maturity; 148 infants $(22.9 \%)$ were of $28-31$ weeks' maturity, $\vec{\omega}$ $144(22 \cdot 3 \%) 32-36$ weeks' maturity, and $221(34 \cdot 3 \%) 37$ weeks or $\bar{O}$ more of maturity (table IV).

TABLE I-Distribution of causes of neonatal deaths in Northern Ireland during 1974-5

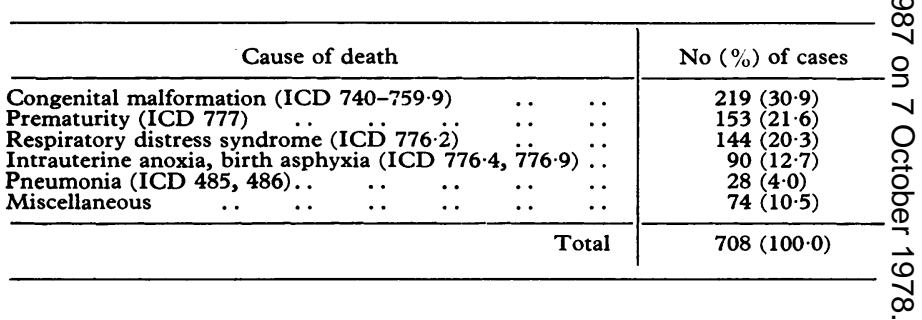

TABLE II-Distribution of neonatal deaths from different types of congenital malformation

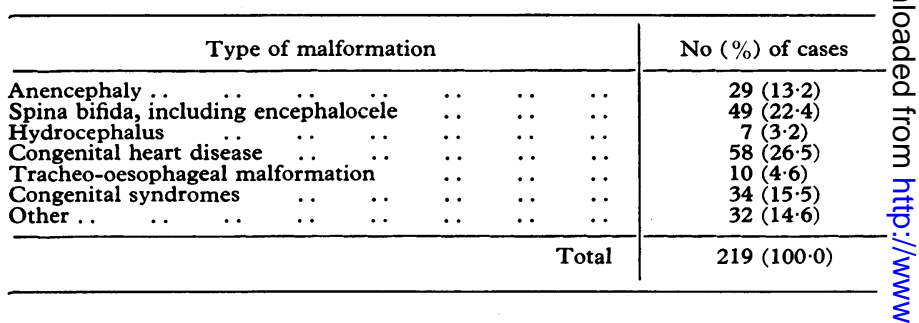

TABLE III-Distribution of 567 neonatal deaths in Northern Ireland during 1974-5 according to birth weight

\begin{tabular}{|c|c|c|c|}
\hline Weight (g) & No $(\%)$ of cases & Weight $(g)$ & No $(\%)$ of cases \\
\hline $\begin{array}{c}<500 \\
500- \\
1000- \\
1500- \\
2000-\end{array}$ & $\begin{array}{r}8(1 \cdot 4) \\
107(18 \cdot 9) \\
126(22 \cdot 2) \\
81(14 \cdot 3) \\
71(12 \cdot 5)\end{array}$ & $\begin{array}{l}2500- \\
3000- \\
3500- \\
4000- \\
4500+\end{array}$ & $\begin{array}{c}70(12 \cdot 3) \\
59(10 \cdot 4) \\
35(6 \cdot 2) \\
8(1.4) \\
2(0.4)\end{array}$ \\
\hline
\end{tabular}

TABLE IV-Distribution of neonatal deaths in Northern Ireland during 1974-5 according to maturity

\begin{tabular}{|c|c|c|c|c|c|c|}
\hline Maturity (weeks): & $<24$ & $24-27$ & $28-31$ & $32-36$ & $\geqslant 37$ & Total \\
\hline No $(\%)$ of cases & $18(2 \cdot 8)$ & $114(17 \cdot 7)$ & $148(22 \cdot 9)$ & $144(22 \cdot 3)$ & $221(34 \cdot 3)$ & $\overline{645(100 \cdot 0)}$ \\
\hline
\end{tabular}

\section{Discussion}

Factors associated with an increased risk of dying in theo perinatal or neonatal period include the social and biological characteristics of the mother, parity, age, social class, abnormakô. obstetric history, toxaemia of pregnancy, antepartum haemor-? rhage, low birth weight, breech delivery, and preterm delivery. ${ }^{6}$

Northern Ireland has more substandard housing, unemployment, and poverty than other parts of the United Kingdom,? 
and action to combat these may bear fruit in several generations through improved health and social conditions of the mother-tobe and newborn infant. We, however, were concerned with the conditions from which children are currently dying in the neonatal period, and an attempt was made to assess whether we can learn from them some ways in which we might begin to reduce neonatal mortality more rapidly.

In Northern Ireland an infant may be born at home or in one of 44 different obstetric units, only one of which provides specialist neonatal intensive care and only five of which have any paediatric staff and special-care facilities. One step in the recent successful French programme ${ }^{8}$ to prevent mortality and morbidity in the newborn was to introduce legislation laying down minimum standards for staffing and equipment in all maternity units. The French recommendation of centralising deliveries into units conducting at least 3000 deliveries a year does not obtain in Northern Ireland, where no obstetric unit delivers 3000 infants a year. Only three units deliver more than 2000 , four deliver between 1000 and 2000 , and the rest deliver fewer than 1000 infants a year; 22 of the units deliver fewer than 500 babies, and nine under 100. Clearly there is a case for rationalising the number of obstetric units and expanding paediatric services if infants are to have immediate access to personnel and equipment necessary for managing perinatal problems.

The major difficulty in this study was in validating and interpreting the certified causes of neonatal death. This arose for two reasons, the first being that the pathology services in Northern Ireland are understaffed and necropsy was performed in fewer than $10 \%$ of cases. Any new organisation of neonatal care in the province should include provision for postmortem examination so that the exact nature of the condition causing death can be ascertained. The second cause of confusion was one of definition. The 1965 International Classification of Diseases included immaturity, dysmaturity, prematurity, and low birth weight under the general heading of prematurity, so the recent revision is welcome.

Congenital malformations, particularly those affecting the neural tube, caused the greatest proportion of deaths in this study. These defects accounted for $30.9 \%$ of all neonatal deaths compared with $22.6 \%$ reported in England and Wales in $1972 .{ }^{\circ}$ Northern Ireland has one of the highest reported incidences of neural tube defect in the world, ${ }^{10}$ and these conditions carry a high mortality. This was undoubtedly a factor in our high perinatal and neonatal death rates. The diagnosis of these conditions is probably accurate since appearances are characteristic, but the same cannot be said for many of the other recorded malformations. Many of the children with congenital heart disease as a certified cause of death were not seen during life by a paediatrician or cardiologist and were not subjected to necropsy, so there must be some doubt about the validity of the diagnosis. Richards et $a^{11}$ found cardiac malformations in $10 \%$ of neonatal deaths, so our figure of $\mathbf{5 8}$ may be lower than expected.

There is a tendency to regard congenital malformation as making an unavoidable contribution to neonatal mortality and morbidity. This is not justified when recent advances in the antenatal diagnosis of some congenital malformations are considered. ${ }^{12}$ Maternal serum $\alpha$-fetoprotein measurement followed by ultrasound examination and amniocentesis in mothers with abnormal concentrations could permit the termination of some pregnancies affected by neural tube malformation, and some chromosomal abnormalities in a birth population could be avoided if amniocentesis were available to older mothers. While these techniques are useful in secondary prevention they are not without risk. Abortion and fetal death have been reported after amniocentesis, ${ }^{13}$ and antenatal misdiagnosis of neural tube defects has occurred. ${ }^{14}$

Neonatal respiratory problems accounted for much of the mortality in this study. Birth asphyxia is an important cause of preventable death and handicap. It has been estimated that infant deaths could be reduced by $8 \%$ and new handicapped infants born each year by $5 \%$ within a comparatively short time by a determined effort to reduce the numbers of asphyxiated newborn. ${ }^{8}$ The detection and treatment of intrapartum asphyxia requires a high degree of skill and a favourable staff-to-patient ratio. It seems unlikely with the numbers of obstetric hospitals now in Northern Ireland that this could be provided on every site. This would be possible if the service were rationalised, and in the interim the extent of the problem might be reduced by early transfer of high-risk pregnancies to the larger centres for delivery.

Forty-two per cent of all the deaths resulted from either prematurity or idiopathic respiratory distress syndrome. These conditions are in many cases amenable to intensive care, which in Northern Ireland is not provided for most infants. The provision of proper care for these babies would require adequate resuscitation and paediatric services at all obstetric centres. This would mean upgrading facilities at peripheral units, together with the development of a regional neonatal centre where those who require more intensive treatment or investigation might be referred. The road system in Northern Ireland is good, and Blake et $a l^{15}$ showed that sick babies can be transported quite successfully if this is well organised by the intensive care unit that is to receive the baby.

Since the period of this study the neonatal mortality rate has shown no substantial change, the rate for 1976 being 13.3.16 The rate for 1977 is not yet available. No new paediatricians with a special interest in neonatology have been appointed, and the number of intensive-care and special-care cots remains unchanged. The background of civil disorder and social problems persists. It is impossible to measure the effect that the prolonged civil troubles may have had on neonatal mortality rates, but when we consider that in 1968 the rates for England and Wales, Scotland, and Northern Ireland were 12,13 , and 16 respectively ${ }^{1}$ ? and in 1976 were 10,10 , and $13^{16}$ it appears that the troubles are not preventing us from keeping pace with improvements possible in other areas of the United Kingdom, even though our absolute position remains substantially worse.

We thank all those obstetricians, paediatricians, and general practitioners who most generously allowed us to examine the records of mothers and babies in their care, and also thank Mrs Iris Hay and staff for help with the coding and analysis of data.

\section{References}

1 Department of Health and Social Security, Department of Education and Science, and Welsh Office, Fit for the Future: Report of the Committee on Child Health Services (chairman, Professor S D M Court), Cmnd 6684-1. London, HMSO, 1976.

2 Thompson, T, and Reynolds, J, Fournal of Perinatal Medicine, 1977, 5, 59.

3 Working Party on the Prevention of Early Neonatal Mortality and Morbidity, Report, HC(76)40. London, DHSS, 1976.

4 DHSS, Report of the Expert Group on Special Care for Babies. Reports on Public Health and Medical Subjects, No 127. London, HMSO, 1971.

5 World Health Organisation, Manual of the International Statistical Classification of Diseases, Injuries and Causes of Death, 8th revn, vol 1 . Geneva, WHO, 1967.

6 World Health Organisation, Prevention of Perinatal Morbidity and Mortality, Public Health Papers, No 42. Geneva, WHO, 1972.

${ }^{7}$ Evason, E, Poverty: The Facts in Northern Ireland, poverty pamphlet 27. London, Child Poverty Action Group, 1977.

8 Wynn, M, and Wynn, A, Prevention of Handicap of Perinatal Origin: An Introduction to French Policy and Legislation. London, Foundation for Education and Research in Childbearing, 1976.

${ }^{9}$ Registrar General, Statistical Review of England and Wales, Part I, Tables, Medical. London, HMSO, 1972.

10 Elwood, J H, and Nevin, N C, Ulster Medical fournal, 1973, 42, 213.

11 Richards, M R, et al, Pediatrics, 1955, 15, 12.

12 Brock, D J H, British Medical Bulletin, 1976, 32, 16.

${ }_{13}$ Milunsky, A, Atkins, L, and Littlefield, J W, Obstetrics and Gynecology, $1972,40,104$.

14 Field, B, and Kerr, C, Lancet, 1975, 2, 324

15 Blake, A M, et al, British Medical fournal, 1975, 4, 13.

${ }^{16} 55$ th Annual Report of the Registrar General, 1975, p 31. Belfast, HMSO, 1978.

17 47th Annual Report of the Registrar General, 1968, p 31. Belfast, HMSO, 1969.

(Accepted 18 Fuly 1978) 